\title{
Microbiological Challenge Test of Contamination Caused by Using the PhaSeal System
}

\author{
Koji Hama*1, Tohru Hashida ${ }^{1}$ and Kazusaburo Kataoka² \\ Department of Pharmacy, Kobe City Medical Center General Hospital ${ }^{1}$, \\ School of Pharmacy and Pharmaceutical Sciences, Mukogawa Women's University ${ }^{2}$ \\ $\left[\begin{array}{l}\text { Received August 13, } 2012 \\ \text { Accepted November 29, } 2012\end{array}\right]$
}

In the Japanese Pharmacopoeia, there are no criteria for multiple uses, such as multidose vials, for rubber stoppers (RS), which may cause bacteriological contamination. To resolve this problem we would like to suggest the use of a closed system (CS), while considering the structure. However, multidose vials are not always kept in an aseptic environment. Hence, it is necessary to assess CS contamination and metal needles, so we compared the microbiological contamination level using Bacillus subtilis between the PhaSeal system (PS) and metal needles.

On the RS of a vial containing distilled water and the top of PS-P21's membrane, $3.0 \times 10^{4}$ spores were prepared ("Bacillus-vial" and "Bacillus-P21"). An unused P21 was attached to the Bacillus-vial (Sample1). A metal needle was vertically inserted into the Bacillus-vial, and each of the puncture and vial inversion operations was carried out once, 5 times, and 10 times (Sample 2-1, 2-5, 2-10). Furthermore, Bacillus-P21 was attached to the Bacillus-vial, and PS-N35 was attached to Bacillus-P21. Each puncture was carried out once, 5 times, and 10 times (Sample 3-1, 3-5, 3-10). Viable bacterial cells were counted using the pour plate method.

Bacterial cells were detected in all samples; however, bacterial cells were not detected from control vials that were not administered prepared spores. The B. sublitis contamination rates of Sample 1/2-1/2-5/2-10/3-1/3-5/3-10 were 0.7/1.4/3.1/1.9/0.1/3.2/5.0 \%, respectively.

This study suggests that PS is almost equivalent to metal needles at up to 5 punctures in terms of microbiological contamination when PS is used multiple times for multidose preparation under preparation conditions where the vials are susceptible to bacterial contamination.

Key words — multidose vials, closed system (the PhaSeal system), needle-punctured multiple times, microbiological contamination

\section{Introduction}

Although the only current multidose formulation for an anticancer drug in Japan is Mitxsantorone, we have studied the possibility of introducing multidose vials for other anticancer drugs in Japan. ${ }^{1}$ The rubber stopper is needle-punctured multiple times when the same vial is continuously used, such as with multidose vials. However, there are no criteria for multiple uses of rubber stoppers in the Japanese Pharmacopoeia. In the last few years, a closed system has been evaluated as a useful tool for preventing exposure of anticancer drugs during preparation ${ }^{2-5)}$ and has been used in many hospitals in Japan. We suggest using a closed system during preparation of multidose vials because the damage level to the rubber stopper during preparation of multidose vials using a closed system is structurally similar to single dose vial preparation. The needle of the closed system is passed through the same spot of the rubber stopper even with multiple uses. However, the storage conditions of multidose vials attached to the closed system are not always kept in an

* 2-1-1, Minatojima-minamimachi, Chuo-ku, Kobe-shi, Hyogo, 650-0047 Japan 
aseptic environment. Although a metal needle penetrates only one point through the rubber stopper for one preparation, the closed system is penetrated at two points through both the rubber stopper and part of the closed system.

Generally, the vial is contaminated with a very small amount of bacteria from the rubber stopper surface after some needle punctures. Therefore, when multidose vials attached to a closed system are used for multiple preparations and the storage conditions are not kept aseptic, the contamination rate when using a closed system may be higher than the rate when using a metal needle. Therefore, it is necessary to assess in terms of contamination whether a closed system is superior to a metal needle. The reason for this is that bacterial contamination should be minimized when using a vial multiple times.

Although microbiological contamination risk has been reported for the closed system when puncturing the vial with the needle, ${ }^{6}$ bacterial contamination of the vial through the rubber stopper requires further study.

In Japan, the storage conditions of vials and the preparation environment of anticancer drugs are not required to be aseptic according to the indication of use. Therefore, in this study, we investigated the microbiological contamination of the PhaSeal system (PS), a closed system, and metal needles when the same vial was punctured by a needle multiple times under non-aseptic conditions using Bacillus subtilis.

\section{Materials and Methods}

\section{Preliminary study}

An appropriate inoculating bacterial mass (bacterial concentration) was investigated to establish the amount of bacteria contaminating the vial contents as described below.

\subsection{Advance preparation (artificial contamination)}

B. subtilis NBRC 3134, a challenge strain, was cultured on Trypto-soy agar (Eiken Chemical Co., Ltd.) at $30 \pm 1{ }^{\circ} \mathrm{C}$ for $7-10$ days, and bacterial cells were suspended in physiological saline. The suspension was heated at $70 \pm 1^{\circ} \mathrm{C}$ for 20 minutes to kill vegetative cells. The suspension was then centrifuged, the supernatant was removed and cells were suspended in physiological saline. The suspension (spores in saline) was adjusted to bring the number of spores to $2.6 \times 10^{8} / \mathrm{mL}$. B. sublitis (the challenge strain selected in this study has spores about $0.001 \mathrm{~mm}$ in diameter $\left.{ }^{7}\right)$. Each spore was a rice-like shape and smaller than the vegetative cell, so that vials were easily contaminated with spores during the operations described below. B. sublitis was selected because it is relatively safe to handle. It was considered that there would be little influence on the results of this study due to the round spores on the rubber stopper because they could easily line up in a similar direction compared with the bacillus when bacteria on the rubber stopper were pushed into the vial by the needle.

Ten milliliters of distilled water for injection were placed in a vial, and vials to be tested were sterilized in an autoclave at $115^{\circ} \mathrm{C}$ for 30 minutes. The spore suspension $(0.01 \mathrm{~mL})$ was dropped onto the center of the rubber stopper $(0.72 \mathrm{~cm}$ in diameter, $0.41 \mathrm{~cm}^{2}$ in area) of the vial which contained sterilized distilled water for injection. The rubber stopper of the vial was then dried at $30 \pm$ $1^{\circ} \mathrm{C}$ for 2 hours. The operation produced a vial with $2.6 \times 10^{6}$ spores on its rubber stopper.

\subsection{Bacterial contamination due to needle puncture}

PS, a closed system used to prepare anticancer drugs was used as follows:

A component called a "Protector" was attached to the vial and a component called an "Injector 
Luer Lock" instead of a needle was attached to the syringe. When the Injector Luer Lock was attached to the top of the Protector P21 ("P21"), the needle within the Injector penetrated through the membrane of the Protector and into the rubber stopper of the vial.

In a safety cabinet, unused P21 (Lot No.: 9260847) was attached to a vial contaminated with dried bacteria and they were attached to an unused Injector Luer Lock N35 ("N35” (Lot No.: 9420487)). The vial was repeatedly inverted 5 times. Distilled water in the vial was collected with a syringe attached to N35 and used as a testing sample (Sample pre-P21, $\mathrm{n}=5$ ).

Similarly, a metal needle (Nipro 18G S.B. (Lot No.: 10J082)) was vertically inserted into the contaminated vial once and the vial was repeatedly inverted 5 times. After removing the rubber stopper, distilled water in the vial was used as a testing sample (Sample pre-Needle, $\mathrm{n}=5$ ).

\subsection{Viable cell count}

Viable bacterial cells per $5 \mathrm{~mL}$ sample collected were counted using the pour plate method. If viable bacterial cells per $5 \mathrm{~mL}$ sample were more than 300 , it was specified as "Too numerous to count (TNTC), " and viable bacterial cells per 0.1 $\mathrm{mL}$ sample were counted.

Based on the data obtained as described above, the bacterial concentration used in the main study was determined: the amount of bacteria dropped on the rubber stopper was determined to achieve an appropriate viable cell count per $5 \mathrm{~mL}$.

\section{Main study}

\subsection{Preparations}

Spore suspensions were prepared as described in the Preliminary study and were adjusted with distilled water to bring the number of spores to $3.0 \times 10^{6} / \mathrm{mL}$. Using the spore suspension, a vial containing distilled water for injection and with $3.0 \times 10^{4}$ spores on its rubber stopper was prepared (the "Bacillus- vial").

In addition, at the top of $\mathrm{P} 21$ where a membrane was seated, $0.01 \mathrm{~mL}$ of the spore suspension was dropped onto a site of the membrane into which an N35 needle was inserted. Then, the membrane was dried at $30^{\circ} \mathrm{C}$ for 2 hours ("BacillusP21"). The number of bacteria on the membrane was the same as that of the rubber stopper of the vial (Fig. 1).

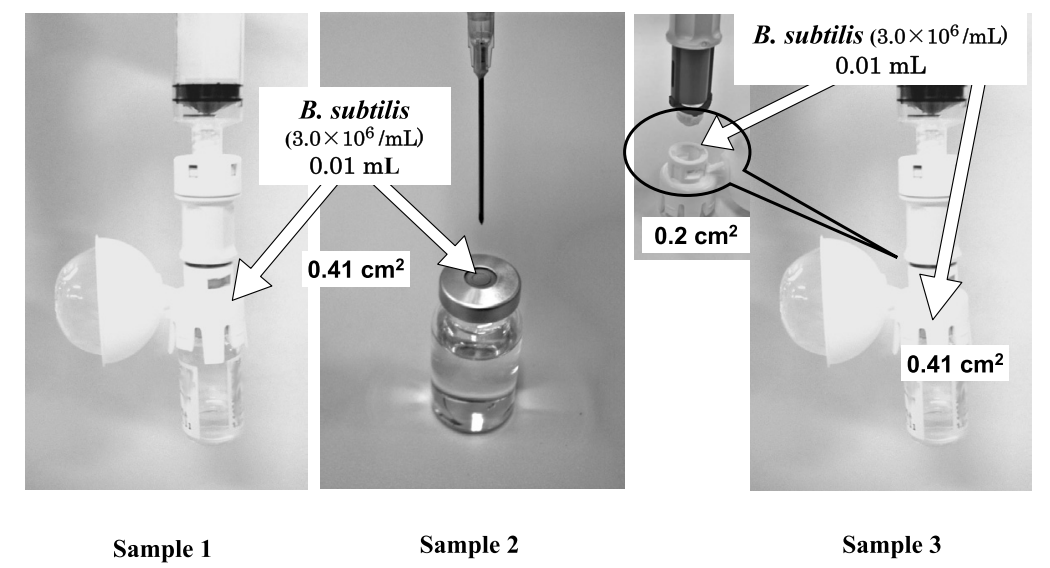

Fig. 1 Sites onto which each B. Subtilis sample was dropped

B. subtilis- containing suspension was dropped on the rubber stopper or the membrane of PhaSeal P21, which is indicated by arrows, and the rubber stopper and the membrane were dried. Sample 1: B. subtilis on the rubber stopper + PhaSeal P21

Sample 2: B. subtilis on the rubber stopper

Sample 3: B. subtilis on the rubber stopper and the membrane of top of the P21 


\subsection{Contamination with bacteria due to needle puncture}

In the safety cabinet, an unused P21 and N35 were attached to the Bacillus-vial and the vial was repeatedly inverted 5 times. An unused N35 was attached to a syringe, and distilled water in the vial was collected with the syringe and used as a testing sample (Sample $1, \mathrm{n}=5$ ).

Similarly, a metal needle (Nipro 18G S.B. (Lot No.: 10J082)) was vertically inserted into the Bacillus-vial and the vial was repeatedly inverted 5 times. Each of the puncture and vial inversion operations was carried out once, 5 times, and 10 times, using an unused needle every time. In addition, the RS and the P21's membrane where the spore suspension was prepared and dropped were not disinfected at any time. After removing the rubber stopper, distilled water in the vial was used as a testing sample (Sample 2-1, 2-5, 2-10, $\mathrm{n}=5$ for each). The number of punctures was up to 10 times because multidose vials are used multiple times.

Assuming use of the closed system under actual conditions, Bacillus-P21 was attached to the Bacillus-vial, and an unused N35 was then attached to Bacillus-P21. The vial was inverted 5 times. After inversion, each of the puncture and vial inversion operations was carried out once, 5 times, and 10 times, using an unused N35 every time. In addition, the RS and the P21's membrane where the spore suspension was prepared and dropped were not disinfected at any time. Distilled water in the vial manipulated as described above was collected through the N35 and used as a testing sample (Sample 3-1, 3-5, 3-10, $\mathrm{n}=5$ for each).

In the safety cabinet, a vial containing sterile distilled water for injection and with a rubber stopper uncontaminated with bacteria was punctured with an unused metal needle. Each of the puncture and vial inversion operations was carried out 10 times in total, using an unused metal needle every time. After removing the rubber stopper, distilled water in the vial was used as a testing sample (Control 1, $\mathrm{n}=5$ ). Similarly, an unused P21 was attached to a vial containing sterile distilled water for injection, and the P21 was punctured with an unused N35. Each of the puncture and vial inversion operations was carried out 10 times in total, using an unused N35 every time. Distilled water in the vial was collected into a syringe through the N35 and was used as a testing sample (Control 2, $\mathrm{n}=5$ ).

\subsection{Viable cell count}

Viable bacterial cells per $5 \mathrm{~mL}$ sample collected were counted using the pour plate method. If viable bacterial cells per $5 \mathrm{~mL}$ sample numbered more than 300 , it was specified as TNTC, viable bacterial cells per $\mathrm{mL}$ sample were counted, and the count result was converted to the number per $5 \mathrm{~mL}$ sample.

\section{Comparison}

The results of the preliminary study, Sample 1 and Sample 2-1 were compared and studied regarding the bacterial contamination of vials caused by using the metal needle through the rubber stopper of the vial or by using the PS P21. In addition, the contamination levels of vials were compared when the number of punctures increased using the metal needle or the PS. Finally, the contamination levels of vials were compared when the number of punctures was the same between the metal needle and the PS. Each comparison was examined with the Student's $t$ test or Tukey test. 


\section{Results}

\section{Preliminary study}

The number of bacterial cells per $5 \mathrm{~mL}$ sample collected was TNTC in all the samples. The viable cell count per $0.1 \mathrm{ml}$ sample collected was TNTC in the 5 metal needle sample results except for 2 results. Each sample was diluted 10-fold except for the two metal needle samples and a viable cell count was carried out again. The results are shown in Fig. 2 and were as follows:

Sample pre-P-21: $(1.4 \pm 0.3) \times 10^{3} / 0.1 \mathrm{~mL}$ Sample pre-Needle: $(3.5 \pm 1.3) \times 10^{2} / 0.1 \mathrm{~mL}$

$($ Mean \pm SD)

Based on the above, the concentration of spore suspensions in the main study was determined to be about $1 / 100$ of the concentration of the Preliminary study.

\section{Main study}

Bacterial cells, $(1.1 \pm 1.8) \times 10^{2} / 5 \mathrm{~mL}($ Mean \pm $\mathrm{SD})$, were detected from Sample 1 in which P-21

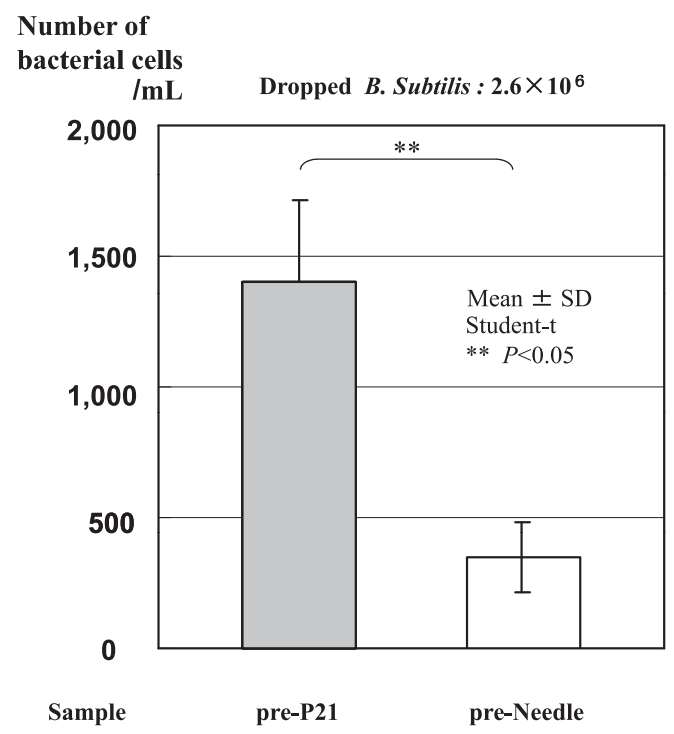

Fig. 2 The number of bacterial cells detected from the needle-punctured vials (Preliminary study) was inserted into the Bacillus-vial once. Bacterial cells, $(2.1 \pm 3.8) \times 10^{2} / 5 \mathrm{~mL},(4.6 \pm 3.6) \times 10^{2} / 5$ $\mathrm{mL}$ and $(2.8 \pm 2.6) \times 10^{2} / 5 \mathrm{~mL}$, were detected from Sample 2-1, Sample 2-5 and Sample 2-10, respectively, in which the metal needle was inserted into the rubber stopper. Bacterial cells, (3.9 \pm 3.6) $\times 10^{1} / 5 \mathrm{~mL},(9.6 \pm 6.7) \times 10^{2} / 5 \mathrm{~mL}$ and $(1.5$ $\pm 0.6) \times 10^{3} / 5 \mathrm{~mL}$, were detected from Sample 3-1, Sample 3-5 and Sample 3-10, respectively, in which Bacillus-P21 was attached to the Bacillusvial and N35 was inserted into Bacillus-P21. On the other hand, no bacterial cells were detected from Controls 1 and 2, in which the vial was uncontaminated with bacteria and unused metal needles, unused P21s and N35s were used. There was no significant difference between Sample 1 and Sample 2-1, and among Sample 2-1, Sample 2-5, and Sample 2-10 in the number of bacterial cells detected. Among Sample 3-1, Sample 3-5 and Sample 3-10, the number of bacterial cells detected was significantly higher in Sample 3-5 and Sample 3-10 than in Sample 3-1. The number of bacterial cells was significantly higher in Sample 3-10 than in Sample 2-10, both of which were needle-punctured 10 times (Figs. 3 and $\mathbf{4}$ ).

B. sublitis contamination rates of the vials were calculated as follows:

The number of bacterial cells per $10 \mathrm{~mL}$, the volume of distilled water for injection in the vial, was calculated by dividing the average values of bacterial cell count results by $10 \mathrm{~mL}$. The number of bacterial cells per $10 \mathrm{~mL}$ was then divided by the initial bacterial cell count that was the number of bacteria used for contamination $\left(3.0 \times 10^{4}\right)$ to give B. sublitis contamination rates. B. sublitis contamination rates were $0.7 \%$ for Sample 1, 1.4\% for Sample 2-1, 3.1\% for Sample 2-5, and 1.9\% for Sample 2-10, and 0.1\% for Sample 3-1, 3.2\% for Sample 3-5, and 5.0\% for Sample 3-10 (Table 1). 


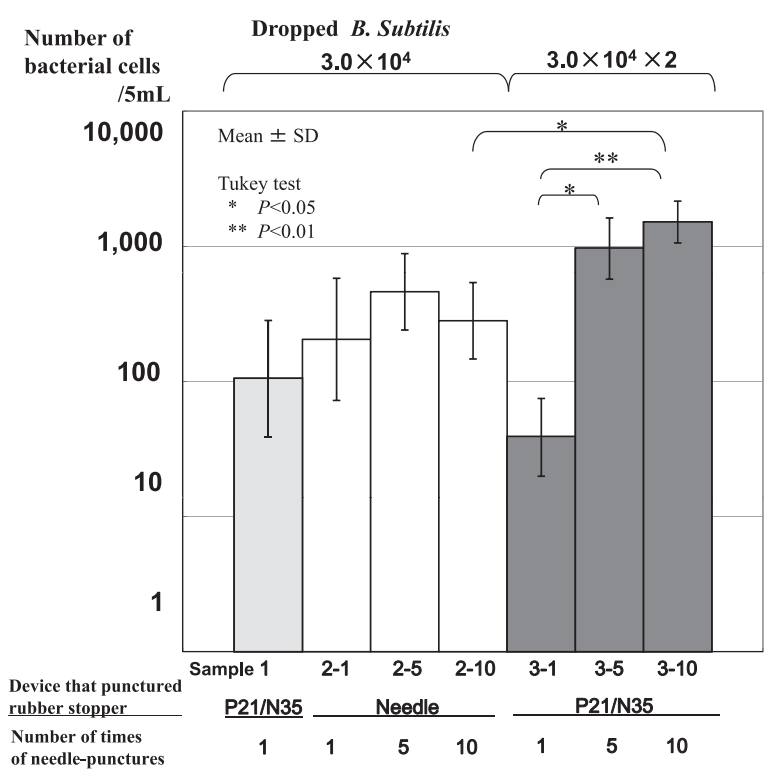

Fig. 3 The number of bacterial cells detected from the needle-punctured vials (Main study)

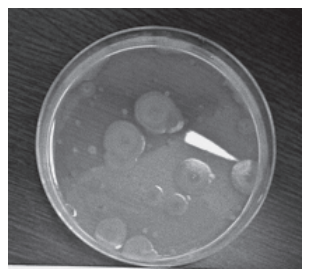

Sample 1

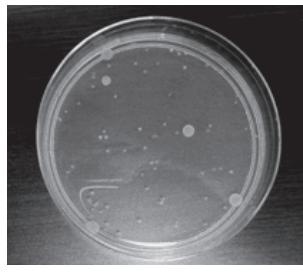

$3-1$

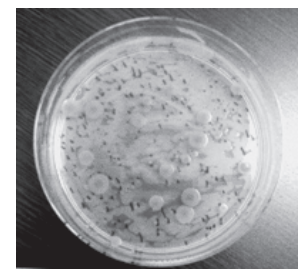

$2-5$

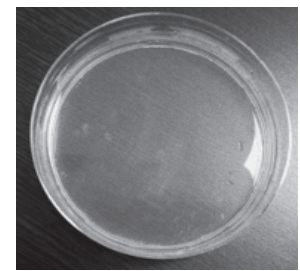

control
Fig. 4 Photos showing B. subtilis colonies on each sample

Table 1 B. subtilis contamination rates of the vials

\begin{tabular}{|c|c|c|c|c|}
\hline Sample & Device & $\begin{array}{l}\text { [The average values } \\
\text { of bacterial cell count/ } \\
10 \mathrm{~mL} \text { ]/ The initial } \\
\text { bacterial cell count }\end{array}$ & $\begin{array}{c}\text { B. sublitis } \\
\text { contamination } \\
\text { rates (\%) }\end{array}$ & \\
\hline 1 & $\mathrm{P} 21$ & $210 / 30000$ & $0.7 \%$ & \\
\hline $2-1$ & Needle & $410 / 30000$ & $1.4 \%$ & \\
\hline $2-5$ & & $922 / 30000$ & $3.1 \%$ & \\
\hline $2-10$ & & $562 / 30000$ & $1.9 \%$ & \\
\hline $3-1$ & $\mathrm{P} 21+\mathrm{N} 35$ & $78 / 60000$ & $0.1 \%$ & \\
\hline $3-5$ & & $1924 / 60000$ & $3.2 \%$ & \\
\hline $3-10$ & & $3024 / 60000$ & $5.0 \%$ & $* *$ \\
\hline
\end{tabular}

\section{Discussion}

It was confirmed that both the typical metal needles and the closed system caused bacterial contamination if the needle was inserted into the rubber stopper of the vial. P21 was punctured only once even if it was used multiple times because P21 is directly attached to the vial and is left attached. Considering the actual conditions of the devices being used, we designed the study as follows:

The metal needle is inserted into the rubber stopper of the vial a maximum of 10 times.

Needle puncture of P21 was done only once. N35 was inserted into the same sites of the P21 membrane and the rubber stopper of the vial 10 times.

It was found that when metal needles are used, bacterial contamination in the vials tended to increase with increasing numbers of punctures, although the number of bacterial contaminants did not show a big difference from 1-10 punctures.

The metal needles used in the study were $18 \mathrm{G}$ (S.B. $1.2 \mathrm{~mm}$ in diameter) and the N35s were 18G. P21 and the metal needle did not show any difference in the number of bacterial contaminants in the vial, despite the fact that a slightly larger 16G (1.6 $\mathrm{mm}$ in diameter) was used for $\mathrm{P} 21$, according to the manufacturer's instructions. In the preliminary study in which the rubber stopper was punctured only once, the preliminary result was different from the main study result in that the metal needle had a significantly smaller number of bacterial contaminants than P21. This is presumably because in the preliminary study, the number of bacterial contaminants on the rubber stopper was 67 times the number of the main study, suggesting that the diameter of the needles could affect bacterial contamination if the rubber 
stopper was heavily contaminated. However, it is suggested that in the main study in which the number of bacterial contaminants was smaller than that of the preliminary study, the diameter of the needles did not affect the degree of contamination.

The result for Sample 3 shows that the PS had an significantly increased number of bacterial contaminants in the vials with increasing numbers of punctures from one to 5 to 10 times, although the PS did not show a big difference from the metal needle in the same number of punctures up to 5 times. However, PS had an increased number of bacterial contaminants after 10 punctures in comparison to the metal needle. This could possibly be related to the following facts:

(1) Two needles, P21 and N35, were used in the $\mathrm{PS}$, so that $B$. sublitis contaminants were dropped on both the rubber stopper and the P21 membrane. (2) The P21 membrane has a smaller area, which leads to higher concentration of bacterial contaminants than the rubber stopper, even though the number of bacteria in the drop is the same for both the stopper and the membrane, and (3) The PS has a structure characterized by the fact that N35 is firmly attached to the P21 membrane.

According to the stipulated Japanese Industrial Standards, antibacterial activity and efficacy are determined by a difference in the number of bacteria of more than 2 logarithmic value units (Japanese Industrial Standards Committee. “JISZ2801 Antibacterial products-Test for antibacterial activity and efficacy": 2012/05/21 Updated version, http://www.jisc.go.jp/app/pager?id=4972, cited 22 July, 2012.).

Although the standards do not directly apply to this study, the number of bacteria used was not significantly different even if the study is inter- preted according to the standards.

In the airborne bacteria and surface testing performed by medical institutions themselves in Japan, 274-9680/100 $\mathrm{cm}^{2}, 1 \times 10^{1}-4.8 \times 10^{2} \mathrm{CFU} /$ $20 \mathrm{~cm}^{2}$, or $44-64 \mathrm{CFU} / 10 \mathrm{~cm}^{2}$ has been reported. ${ }^{8-10}$ The clean-room of the Pharmaceutical Department of Kobe City Medical Center General Hospital holds a Class 10000 specification. The testing reports and our study conditions indicate that the study was conducted in rather stringent conditions. We believe that the rubber stopper and the small area of the P21 membrane would usually have a few bacterial contaminants if bacteria were present on these components. In addition, cleaning and disinfecting are routinely performed using ethanol disinfectants and the like prior to the preparation of vials. Cleaning with disinfectants reduces the number of bacterial contaminants due to the physical wiping motion so that the number of bacteria on the rubber stopper and P21 membrane may be very limited.

The study by K. De Prijck et al. found that the amount of contamination in the vial was not significantly different between PS and a metal needle for one needle puncture. However, after 10 needle punctures, the PS had less bacteria than the metal needle. Prijcks' study showed opposite results to our study. In their study, the bacteria were prepared on a PS membrane, where a PS Protector and Injector connect. However, in our study, the spores were prepared at two areas, on the rubber stopper and on P21's membrane. Because of that, the vial contamination due to PS may have been worse at the rubber stopper than the P21's membrane. Furthermore, this confirmed that PS did not guarantee total sterility of the vial contents.

In preparation in an environment such as a safety cabinet or clean-room, contamination caused by the preparation of multidose vials after 
needle puncture is limited only to the rubber stopper of the vial when sterile P21s and N35s are opened in these environments. In the preparation in the safety cabinet where the rubber stopper was appropriately disinfected, no bacterial contamination occurred on either the metal needles or the PS.

This study revealed the following regarding the risks of multidose vials of anticancer drugs in the Japanese market. It was suggested that PS is almost equivalent in terms of microbiological contamination to metal needles for up to 5 punctures. Furthermore, it was also suggested that the P21 membrane and the rubber stopper surface should be disinfected with disinfectants to remove bacteria that could potentially contaminate these surfaces and it is desirable for multidose vials to be prepared in an aseptic environment.

\section{Acknowledgement}

The study is financially supported by Carmel Pharma Japan (current Becton, Dickinson and Company).

\section{Conflict of Interest}

There is no conflict of interest for the individuals and the organizations that could have affected fair decisions and judgments in planning, conducting and publicizing this study.

\section{References}

1) Hama K, Kurokawa M, Kataoka K, Economic Benefits of Using Residual Anticancer Agents Based on Medical Fee Calculation Procedure And Microbiological Considerations, Jpn J Pharm Health Care Sci, 2009, 35, 57-63 (in Japanese).
2) Yoshida J, Tei G, Mochizuki C, Masu Y, Koda S, Kumagai S, Use of a Closed System Device to Reduce Occupational Contamination and Exposure to Antineoplastic Drugs in the Hospital Work Environment, Ann Occup Hyg, 2009, 53, 153-160.

3) Sessink PJ, Connor TH, Jorgenson JA, Tyler TG, Reduction in surface contamination with antineoplastic drugs in 22 hospital pharmacies in the US following implementation of a closed-system drug transfer device, J Oncol Pharm Practice, 2010, 17, 39-48.

4) Siderov J, Kirsa S, McLauchlan R, Reducing workplace cytotoxic surface contamination using a closed-system drug transfer device, J Oncol Pharm Practice, 2010, 16, 19-25.

5) Favier B, Labrosse H, Gilles-Afchain L, Cropet C, Perol D, Chaumard N, Latour JF, Hild P, The PhaSeal system: Impact of its use on workplace contamination and duration of chemotherapy preparation, J Oncol Pharm Pract, 2012, 18, 37-45.

6) Prijck KD, D’Haese E, Vandenbroucke J, Coucke W, Robays H, Nelis HJ, Microbiological challenge of four protective devices for the reconstitution of cytotoxic agents, Lett Appl Microbiol, 2008, 47, 543-548.

7) Kondo Y, Kurihara H, Yamada A, Takaoka D, Takizawa K, Yasuda M, Adsorption of Some Bacteria to Positively-Charged Carbon Fiber Electrode, The Journal of the Surface Finishing Society of Japan, 2005, 56, 158-163 (in Japanese).

8) Ikeda K, Murata M, Katsuura M, Kori T, Yamamoto K, Kataoka K, Kurokawa N, Evaluation of the Disinfection Method for Environmental Control of the Drug Preparation Room in the Hospital Pharmacy and Study on the Residual Efficacy of Disinfectants, J Antibact Antifung Agents, 1999, 27, 217-222 (in Japanese).

9) Ichiman Y, Murakami J, Kashikura K, Environmental Indices of Microbiological Contamination at Tsukuba College of Technology Clinic, Departmental Bulletin Paper of Tsukuba College of Technology Clinic, 2000, 7, 191-195 (in Japanese).

10) Nakanishi Y, Sakurai N, Koike K, A Microbiological Investigation at the First Year of The University Hospital for Hospital-Acquired Control Precautions. Bulletin Paper of Ibaraki Prefectural University of Health Sciences, 1998, 3, 59-65 (in Japanese). 